Lisbon - Malacca Port Cities Twin Conferences 2019 / 2020

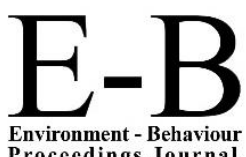
Proceedings Journal
AicQoL2020Malacca

ASLI (Annual Serial Landmark International) Conferences on QoL2020

https://www.amerabra.org; https://fspu.uitm.edu.my/cebs; https://www.emasemasresources.com

8th AMER International Conference on Quality of Life

Mahkota Hotel Melaka, Malacca, Malaysia, 18-19 Mar 2020

(Due to the Covid-19 lockdown, paper virtually presented on 25 Mar 2020)

\title{
Local Knowledge for Global Actions: The role of traditional ecological knowledge in climate change adaptation
}

\author{
Nadzirah Hosen ${ }^{1}$, Hitoshi Nakamura ${ }^{2}$ \\ Shibaura Institute of Technology, Japan \\ Email of All Authors: na17506@shibaura-it.ac.jp, nakamu-h@shibaura-it.ac.jp \\ Tel of 1 st Author:+60127767871
}

${ }^{1}$ Graduate School of Engineering and Science, ${ }^{2}$ Department of Planning, Architecture and Environmental Systems,

\begin{abstract}
The scale of climate change put indigenous people at higher risk than the others. Nonetheless, due to their intimate knowledge of their land, traditional ecological knowledge (TEK) held by the indigenous peoples may be the key to combating climate change. This article aims to explain the role that TEK plays in adapting to climate change. Document review included grey literature alongside peer-reviewed literature and project websites related to indigenous knowledge in climate change adaptation. The findings show that TEK not only helps indigenous people cope with environmental and climate pressures, but the knowledge system fosters resilience of socio-ecological systems.
\end{abstract}

Keywords: climate change adaptation; traditional knowledge; traditional ecological knowledge; resilience

eISSN: 2398-4287 @ 2020. The Authors. Published for AMER ABRA cE-Bs by e-International Publishing House, Ltd., UK. This is an open access article under the CC BYNC-ND license (http://creativecommons.org/licenses/by-nc-nd/4.0/). Peer-review under responsibility of AMER (Association of Malaysian Environment-Behaviour Researchers), ABRA (Association of Behavioural Researchers on Asians) and cE-Bs (Centre for Environment-Behaviour Studies), Faculty of Architecture, Planning \& Surveying, Universiti Teknologi MARA, Malaysia.

DOI: https://doi.org/10.21834/e-bpj.v5i13.2059

\subsection{Introduction}

The Planet has undergone rapid warming in the last few decades, with record high temperatures in the previous decade alone (Scripps Institution of Oceanography, 2017). The current warming trend is the result of human activities that date back to the late 19th century. $97 \%$ of climate scientists agree that human actions have contributed to climate change through the burning of fossil fuels (such as gas, oil, and coal) and other human-induced drivers (Cook, 2016). As a result, significant amounts of greenhouse gases have been released into the atmosphere, thus increasing the possibility of frequent and intense storms, floods, heatwaves, and droughts (IPCC, 2014a). In essence, numerous scholars and observers have claimed that climate change is the most complex environmental challenge that this generation has ever faced. Because climate change impacts every corner of the globe, no one can escape its effects. Unfortunately, Indigenous people, who practice a 'low-carbon' lifestyle, are among the first groups to be directly impacted by climate change.

Globally, climate change has threatened the homes and traditions of Indigenous people. It has also aggravated specific issues (e.g., loss of land and resources) as well as marginalised politics and economics, discrimination, and unemployment. Nonetheless, despite the vulnerabilities that they face, Indigenous people have exhibited creative and unique ways of adapting to environmental changes (Nakashima et al., 2012). It is a direct result of their multi-generational experience and collective knowledge of the land, sky, and sea, which makes them exceptional observers and interpreters of climate change (Raygorodetsky, 2011; Wildcat, 2014). Historically, these communities have encountered various environmental uncertainties, resource limitations, and exposure to extreme weather (Byg \& Salick, 2009). However, as always, indigenous people make detailed observations about their local surroundings, share experiences and plan for the future (Hosen et al., 2019; Hosen et al., 2020). Their intimate connection with nature makes them more sensitive to the

eISSN: 2398-4287 @ 2020. The Authors. Published for AMER ABRA cE-Bs by e-International Publishing House, Ltd., UK. This is an open access article under the CC BYNC-ND license (http://creativecommons.org/licenses/by-nc-nd/4.0/). Peer-review under responsibility of AMER (Association of Malaysian Environment-Behaviour Researchers), ABRA (Association of Behavioural Researchers on Asians) and cE-Bs (Centre for Environment-Behaviour Studies), Faculty of Architecture, Planning \& Surveying, Universiti Teknologi MARA, Malaysia.

DOI: https://doi.org/10.21834/e-bpj.v5i13.2059 
rhythms of the seasons. Thus, it enables them to cope with any change based on century-old knowledge (McLean, 2012) or traditional ecological knowledge (TEK). For Indigenous people, TEK is the root of resilience, i.e., their capacity to adapt to environmental change based on an in-depth understanding of the land (Scaddan, 2008). Essentially, TEK is an essential way of knowing, which may contribute to climate change assessment and adaptation efforts based on local responses. However, despite its relevance, TEK remains one of the least understood components of recent climate change adaptation initiatives (Nalau et al., 2018). Many earlier studies addressed TEK in the management and protection of natural resources (e.g. Berkes, 2017; Popp et al., 2019). As such, this paper seeks to examine the role of TEK in the adaptation to climate change among indigenous people. Accordingly, the objectives of this paper are:

1) To explore the role of TEK in the climate change adaptation based on typologies of TEK

2) To develop a conceptual framework illustrating the position of TEK in climate change adaptation and how it contributes to socioecological resilience

\subsection{Literature Review}

\subsection{Definition of TEK}

Different cultures around the world take different views of the natural world which are not scientifically based. These 'other ways of knowing' are often rooted in the traditional belief systems of Indigenous people. They include sophisticated collections of interpretations and information that help societies interact with the natural environment for survival (e.g., hunting, fishing, and gathering; agriculture and medicine and natural phenomena) as well as coping with any environmental changes (Nakashima et al., 2012). Indigenous people consider their environmental management system as a vital part of their cultural identity and social integrity (Mazzocchi, 2006). Some researchers use different terms to describe the body of knowledge of Indigenous people, such as Indigenous knowledge (IK), traditional knowledge, and TEK. However, such words hold slightly different meanings, although they sound a bit similar. Magni (2016), for instance, described IK as the local knowledge of Indigenous people or other particular cultural groups. This term is usually used in the development literature to describe local ways of knowing as opposed to the modern understanding of globalised culture or developmental science (Dudgeon \& Berkes, 2003). Dudgeon and Berkes (2003) have argued that they could use 'traditional knowledge' as an alternative to IK. The term 'tradition' refers to cultural features, customs, or thought processes handed down and thus preserved from generation to generation (Graburn, 2001). In this context, tradition is not static but cumulative and open to change (Nicholas-Figueroa, 2017). In other words, as their surroundings change, a cultural group will adapt to such change. TEK, on the contrary, has been defined as 'a cumulative body of knowledge, practice, and belief, evolving by adaptive processes and handed down through generations by cultural transmission, about the relationship of living beings (including humans) with one another and with their environment' (Berkes, 1993: 4). Thus, TEK is a 'more specific' subset within the larger body of IK literature.

While both IK and TEK emphasise the social patterns of relationships within a cultural group and the environment, TEK adds an ecological element; that is, it focuses on patterns of interaction between humans and nature, as well as on local ways of knowing and interacting with the ecosystem (Dudgeon \& Berkes, 2003). This holistic approach derives from the definition of ecology itself, i.e., the relationship between living organisms and their biophysical environment (Friederichs, 1958). Therefore, every aspect of the local biosphere, including plants, animals, and landforms, can be considered as a part of the community and are therefore treated with respect and honour (Pierotti \& Wildcat, 2000). This body of knowledge generally includes languages, systems of naming and classification, sustainable practices for the use of resources, rituals, Indigenous worldviews, and spirituality (Boven \& Morohashi, 2002; Vinyeta \& Lynn, 2013). Essentially, TEK is cumulative, dynamic, and adaptive. It is also based on the historical experiences of people and is the product of careful observations of ever-changing environmental, economic, social, spiritual, and political conditions that reflect the fact that knowledge of all these aspects is key to survival (Berkes, 2017). Indigenous people believe that TEK is not just knowledge of life, but it is their way of life (McGregor, 2004). As a self-management system, TEK is an environmental source of information that helps Indigenous peoples protect and sustain their way of life. The reason is that it has become the basis for decision-making, particularly in the areas of agriculture, hunting and gathering, resource management, education, the environment, health and food preparation (Nakashima et al., 2012).

\subsection{Role of TEK in climate change adaptation}

Adaptation to climate change has been an understated issue in recent decades since mitigation seems to be more critical (Farber, 2007). Nevertheless, the impacts of climate change are unavoidable despite any mitigation measures that take place, resulting in an urgent need for adaptation. The definition of adaptation is 'the process of adjustment to actual or expected climate and its effects. In human systems, adaptation seeks to moderate or avoid harm or exploit beneficial opportunities. In some natural systems, human intervention may facilitate adjustment to expected climate and its effects' (IPCC, 2014: 1758). Nevertheless, climate change has brought about significant environmental changes worldwide and needs multi-level adaptation strategies (i.e., global, regional, and local levels) (Kettle \& Dow, 2014). In this regard, Indigenous people have acquired unique knowledge, traditions, and beliefs that link them with the environment, making them a potentially significant contributor to robust action on climate adaptation. TEK provides valuable insights by offering site-specific precision and information to complement scientific data (Vinyeta \& Lynn, 2013). Principally, local interpretations of observed climate change are often more complex and inclusive compared to the conventional climate model, which mainly focuses on anthropogenic greenhouse gas emissions (Salick \& Byg, 2007). Detecting environmental changes and developing strategies for responding to those changes are critical climate actions that TEK can inform (Parrotta \& Agnoletti, 2012). 
Essentially, TEK helps Indigenous people track changes in their local environment through observations based on TEK, and then record their adaptation strategies in response to those changes. Those skills are rooted in TEK typologies. TEK comprises several interrelated analytical levels that reflect the meaning of TEK as a complex of knowledge-practice-belief (Berkes, 1999, 2017; Houde, 2007; McMillen et al., 2014). The first level is factual observation, followed by management practices at the second level, the social organisation at the third level. Finally, the fourth level underpins the first three TEK levels, which form perceptions governing humanenvironmental relationships (Berkes, 2017). This research classifies TEK as (1) local knowledge of the environment, (2) land and resource management systems, (3) social networks and institutions, and (4) worldview and belief systems.

\subsubsection{Local knowledge of the environment}

It includes the knowledge of the flora, fauna, soil, and landscapes, as well as their classification, behaviour, and distribution (Berkes, 2017; Houde, 2007; McMillen et al., 2017). This type of knowledge also includes understanding how the ecosystem functions, the interactions between animals and plants within it, and the role of biophysical parameters in influencing the behaviour of the entire community (Freeman, 1992). Indigenous people are inherently capable of predicting the environment based on their knowledge of animal behaviour, wind speed, sky coverage, and precipitation length (Garay-Barayazarra \& Puri, 2011). For example, the Miriwoong tribe in East Kimberley, Australia, observed the flowers on the Woolegalegeng (silver leaf paperbark tree) to predict the arrival of thunderstorms (Leonard et al., 2013). In the case of Kenyah Badeng farmers on Borneo island, the behaviour of animals such as chickens and frogs, e.g., their noises, are the indicators of coming rains (Garay-Barayazarra \& Puri, 2011). Seasonal changes or cycles can also be observed based on the development and reproduction of flora and fauna. The harvest seasons for some plants, for example, are signalled by the presence of certain insects, bird songs, or flowers. Such phenological phenomena, i.e. weather conditions and seasonal cycles, are vital for Indigenous people because of their connection to the timing of their livelihood activities such as hunting, gathering, farming, and fishing.

Indigenous people need to be aware of even the smallest changes in their environment to survive and must try to respond to those changes. For example, the Miriwoong people know that the flowering of the Gali-Galing (Fern-leaf grevillea) indicates the beginning of the cold season and, thus, respond to this natural event by commencing their traditional burning practices. These practices are motivated by the desire to avoid fires in the late hot season that can have harmful effects on the (Leonard et al., 2013). Indeed, many indigenous communities have a traditional calendar to coordinate their ties with the surrounding land, sea and environment, allowing them to control their activities in different seasons (e.g., Garay-Barayazarra \& Puri, 2011; Leonard et al., 2013; Prober et al., 2011). Generally, this local knowledge can offer very fundamental insights into climate change research. While experimental climate models predict larger-scale environmental changes (i.e., snow and ice melting, sea-level rise, high water temperature, etc.), local non-industrial community observations offer information on smaller, more realistic scales.

Moreover, the intrinsic knowledge of the environment of Indigenous people helps these communities to anticipate changing conditions and situations, which could pose significant risks. Observations and strategies to tackle changes in socio-ecological systems are substantial assets that could guide preparation for adaptation to climate change. They could help in understanding changes, impacts on local communities and their surrounding as well as coping strategies to adapt to those impacts.

\subsubsection{Land and resource management}

Land and resource management systems contain Indigenous people's knowledge about natural resources use and strategies of terrestrial and marine management that have evolved through adaptive processes (Leonard et al., 2013; McMillen et al., 2014). Possession of such systems allows Indigenous communities to prepare for an anticipated hazard by modifying practices and developing appropriate technologies sustainably. In the context of climate change, land and resource management systems are fundamental in terms of building adaptive capacity that contributes to community resilience (McMillen et al., 2014; McMillen et al., 2017). In some cases, such as to avoid food depletion, Indigenous people make an adaptive decision to ration resources that correspond to ecological productivity. For example, a temporal restriction of harvest, including fishing, hunting, gathering, and planting, could be imposed in response to common shortages as well as to allow the renewal of surrounding ecosystems (Berkes et al., 2000; Gómez-Baggethun et al., 2012; Ingty, 2017; McMillen et al., 2014).

Besides, Indigenous management systems often promote diversification that helps in spreading risks across spatiotemporal scales by providing a range of options, thus increasing resilience during shocks (Agrawal, 2008). Examples include swidden agriculture integrated farming, agroforestry, farming and crop varieties (Berkes et al., 2000; Hobson, 1992; Magni, 2016). Such a mixture and selection of various livestock and crop varieties in an integrated farming environment promotes bio-cultural diversity, which is not only resilient to climate change but also has high carbon sequestration levels in the fight against change (Singh et al., 2011). Harvests are also distributed over the seasons to ensure resources are available year-round (Gómez-Baggethun et al., 2012). Another essential strategy is mobility, which reduces spatial risks (Agrawal \& Perrin, 2008). For instance, one of the oldest systems still practised by Indigenous peoples is shifting cultivation, i.e., the communities left the cropland uncultivated for a certain period to restore fertility (Hillel, 2005). Land fertility stimulates crop growth and produces surplus yields. Lastly, resource storage minimises risks over time, especially in reducing food shortages (Agrawal \& Perrin, 2008; Gómez-Baggethun et al., 2012). For example, Indigenous communities in Asia have developed food preservation and storage methods, such as using physical infrastructure to store crops and water, and drying food when food is abundant (AIPP, 2012) 


\subsubsection{Social networks and institutions}

Social networks and institutions are the social mechanisms of TEK that explain the social behaviour of actors in the community when facing disturbance. These structures strongly influence Indigenous livelihoods and adaptation. In the climate change context, customary social institutions and networks promote adaptive capacity within social-ecological systems by buffering disturbances, promoting selforganisation, and facilitating social learning (McMillen et al., 2014). For example, Indigenous people of Ka'ūpūlehu in Hawaii and Dõnana, Spain, both have practised community pooling during hard times. Such pooling entails sharing assets and resources (such as food, natural resources, labour, and infrastructure) across households on a reciprocity basis during scarcity (Agrawal \& Perrin, 2008; Gómez-Baggethun et al., 2012). Consequently, these tribes were able to increase food and resource availability and diversity across space and time, which gave them a buffer against difficulties, especially when resources were scarce, e.g., during a tsunami, drought, and other disturbances (McMillen et al., 2017).

Besides, local leadership and institutions encourage self-organisation that provides the ability to respond to shocks. Strong local leadership and institutions may facilitate efficient allocation systems, promote sustainability, build social cohesion within the community and store collective memory (Brown \& Sonwa, 2015; Gómez-Baggethun et al., 2012; Ingty, 2017). Among tribes in alpine Himalaya, for instance, the traditional institution, namely the Dzumsa, which consists of 12 village representatives from Lachen valley, is very responsive to environmental stresses. It has played a vital role in preventing overuse of resources, maintaining resource buffers, and providing social, ecological, and economic security through resource partitioning (Ingty, 2017). Generally, social institutions and networks based on reciprocity and trust will influence community resilience. In the context of climate change adaptation planning, the strengthening of existing social institutions and networks is crucial. It allows for effective dissemination and facilitation of the exchange of resources and information needed to deal with disturbances (McMillen et al., 2014).

\subsubsection{Worldview and belief systems}

The worldview and belief systems of Indigenous people underpin the first three elements of TEK, thus playing critical roles in TEK as a whole. These systems are the basis for accumulation and transmission of local knowledge and resource management practices as well as social networks and institutions. This transmission often occurs in the form of folklore, taboos, stories, ceremony and rituals, and other related cultural tradition. In other words, worldview and belief systems are a mechanism for transmitting knowledge between generations within a context embedded in social systems (Berkes et al., 2000: 1257). One example of such transmission is the milpa script (related to milpa agroforestry system), which is passed from generation to generation and sustained by mythologies, cultural beliefs, and yearly festivals (Folke \& Berkes, 1998). In practice, these traditions help to build strong social networks and to maintain mutual relations by exchanging and sharing information and resources. They can develop and foster healthy and enduring relationships between the parties by building trust and establishing a bond between the members of the community. (Ziegler, 2007).

Consequently, during hard times, individuals can rely on these reciprocity relationships, thus helping to ensure the resilience of resource access. Kula Ring in Papua New Guinea is an example of a ritual exchange of gifts made from shells (McMillen et al., 2014). Worldviews of Indigenous peoples often involve cultural and spiritual values that promote sharing, reciprocity, and respect that are essential for TEK to work. In essence, these values are the main factors that maintain traditional practices and systems (Swiderska et al., 2011). Generally, the worldview of Indigenous people is fundamental to ensuring the continuity of TEK, especially in the globalised world. Thus, the loss of TEK means the loss of alternative ways of adapting to environmental changes, particularly in the face of climate change.

\subsection{Methodology}

A keyword-based analysis of grey literature, peer-reviewed literature and project websites was conducted. Search keywords include TEK, climate change adaptation, climate change, traditional knowledge, Indigenous adaptation, Indigenous people, adaptive capacity, and resilience. Relevant articles were screened using the following criteria (1) the impact of climate change on Indigenous people; and (2) local strategies in coping with climate change. Then, relevant articles were examined to define TEK, the components of TEK, the role of each element in climate change adaptation, and finally, how the TEK contributes to socio-ecological resilience. As for research limitation, this paper mainly focuses on the social and environmental implications of climate change. The economic aspect is not part of the scope of this study.

\subsection{Findings \& Discussion}

Building on the TEK components described above, we developed a conceptual framework that bridge TEK, climate change adaptation, and socio-ecological resilience, as shown in Fig. 1.

Fig. 1 indicates all of the essential components of the TEK that reinforce adaptation practices of Indigenous communities, namely forecasting, rationing, diversification, mobility, storage, and pooling. These adaptation practices are consistent with local adaptation classification provided by Agrawal (2008), Prasad et al. (2009), and Gómez-Baggethun et al. (2012). These practices are necessary to promote resilience, which plays a role in social and ecological processes that sustain the well-being of the social-ecological system. In this regard, socio-ecological systems contain the interplay between humans and the biophysical environment, which increasingly recognised as a tool to conceptualise human-environment systems and the way it can be governed to be resilient (Berkes et al., 2003; Stokols et al., 2013). In the context of social-ecological systems, resilience denotes the following: (1) The ability of a system to retain its identity, structure, and feedback after encountering a set of change (Walker et al., 2004), and (2) the ability of the system to reconstruct 
after it has crossed a threshold (Folke, 2016). Importantly, a variety of attributes characterise these abilities: (1) ecological diversity; (2) ecosystem services; (3) social capital inclusive of social connections and participation in community groups; (4) self-organisation; and (5) continuous learning in response to environmental change (Folke et al., 2002; Gómez-Baggethun et al., 2012; Walker \& Salt, 2006). As discussed, adaptation practices rooted in TEK has significantly encouraged the development of these attributes.

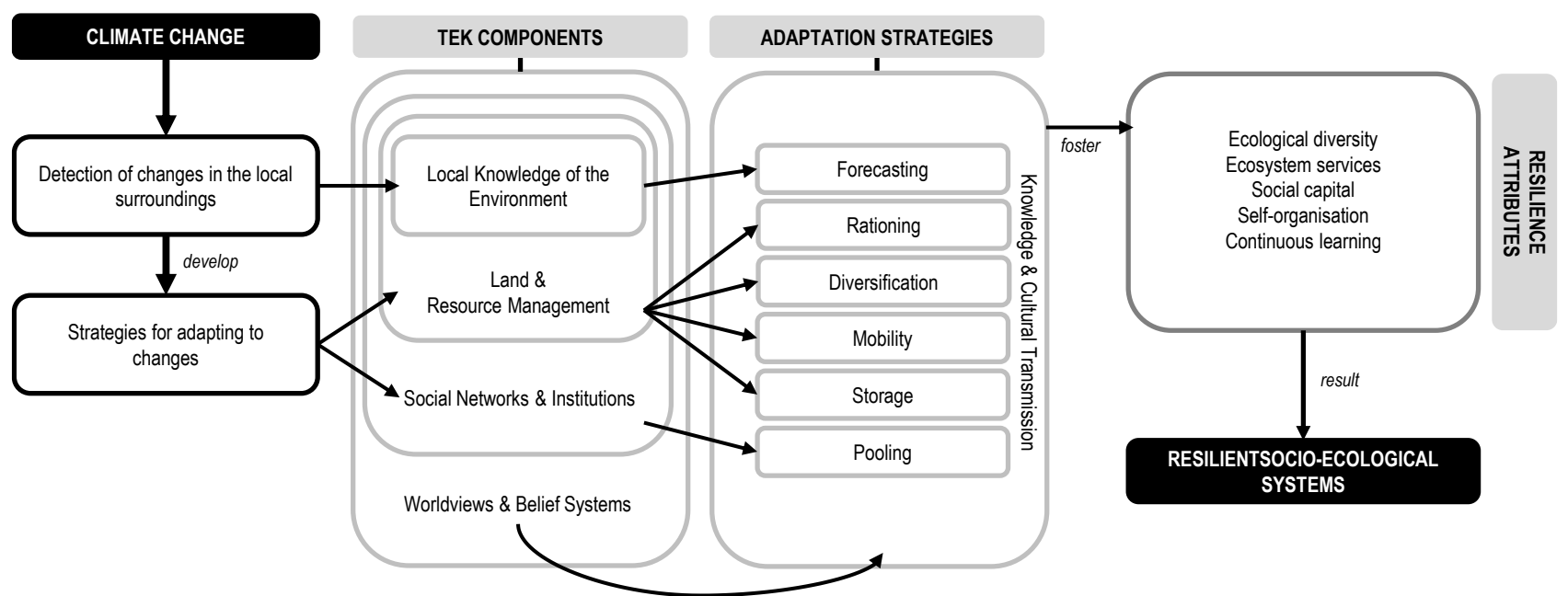

Fig. 1: Bridging TEK, adaptation, and resilience of socio-ecological systems

(Source: Author, 2019)

\subsection{Conclusion \& Recommendations}

Overall, this paper has met the objectives proposed at the beginning of the study. TEK which comprises the local knowledge of the environment; land and resource management; social networks and institutions; and worldviews and belief systems help Indigenous communities identify changes in the climate and establish adaptation strategies specific to the local context. More importantly, these approaches are critical for fostering socio-ecological system resilience. They strengthen the capacity of society to cope with change and sustain ecosystems under unpredictable circumstances, as the knowledge base coexists with socio-ecological systems. Therefore, the framework is useful for guiding place-based research that involves TEK in climate change studies as each component of TEK within the structure has its function to consider. However, future research is required to provide grounded evidence supporting the conceptual framework proposed in this paper.

\section{References}

Agrawal, A. (2008). The Role of Local Institutions in Adaptation to Climate Change. Washington D. C, USA: World Bank.

Agrawal, A., \& Perrin, N. (2008). Climate adaptation, Local Institutions and Rural Livelihoods. In IFRI Working Paper (Vols. W081-6).

AIPP. (2012). Indigenous Peoples and Climate Change Adaptation in Asia. Chiang Mai: AIPP Printing Press.

Berkes, F. (1993). Traditional ecological knowledge in perspective. In J. T. Inglis (Ed.), Traditional Ecological Knowledge: Concepts and Cases (pp. 1-9). Canadian Museum of Nature and the International Development Research Centre.

Berkes, F. (1999). Sacred Ecology: Traditional Ecological Knowledge and Resource Management. Philadelphia, PA, USA: Taylor \& Francis.

Berkes, F. (2017). Sacred Ecology (Fourth). New York, NY, USA: Routledge.

Berkes, F. Colding, J., \& Folke, C. (2000). Rediscovery of Traditional Ecological Knowledge as Adaptive Management. Ecological Applications, 10(5), $1251-1262$. Boven, K., \& Morohashi, J. (2002). Best Practices using indigenous knowledge (K. Boven \& J. Morohashi (Eds.)). Nuffic, The Hague, The Netherlands, and UNESCO/MOST.

Brown, H. C. P., \& Sonwa, D. J. (2015). Rural local institutions and climate change adaptation in forest communities in Cameroon. Ecology and Society, 20(2).

Byg, A., \& Salick, J. (2009). Local perspectives on a global phenomenon-Climate change in Eastern Tibetan villages. Global Environmental Change, 19(2), 156-166.

Cook, J. (2016). Consensus on consensus: a synthesis of consensus estimates on human-caused global warming.

Dudgeon, R. C., \& Berkes, F. (2003). Local Understandings of the Land: Traditional Ecological Knowledge and Indigenous Knowledge. In H. Selin (Ed.), Nature Across Cultures: Views of Nature ami the Environment in Non-Western Cultures (pp. 75-96). Kluwer Academic Publishers.

Farber, D. A. (2007). Adapting to climate change: Who should pay. Journal of Land Use, 23(1), 1-38. 
Folke, C. (2016). Resilience (Republished). Ecology and Society, 21(4).

Folke, C., \& Berkes, F. (1998). Understanding Dynamics of Ecosystem Institution Linkages for Building Resilience.

Folke, C., Carpenter, S., Elmqvist, T., Gunderson, L., Holling, C., \& Walker, B. (2002). Resilience and Sustainable Development: Building Adaptive Capacity in a World of Transformations. Ambio, 31(5), 337-440.

Freeman, M. M. R. (1992). The Nature and Utility of Traditional Ecological Knowledge. Northern Perspectives, 20(1), 9-12 pp.

Friederichs, K. (1958). A Definition of Ecology and Some Thoughts About Basic Concepts. Ecology, 39(1), 154-159.

Garay-Barayazarra, G., \& Puri, R. K. (2011). Smelling the monsoon: Senses and traditional weather forecasting knowledge among the Kenyah Badeng farmers of Sarawak, Malaysia. Indian Journal of Traditional Knowledge, 10(1), 21-30.

Gómez-Baggethun, E., Reyes-García, V., Olsson, P., \& Montes, C. (2012). Traditional ecological knowledge and community resilience to environmental extremes: A case study in Doñana, SW Spain. Global Environmental Change, 22(3), 640-650.

Graburn, N. H. H. (2001). What is Tradition? Museum Anthropology, 24(2/3), 6-11.

Halim, A. A., Jawan, J. A., Ismail, S. R., Othman, N., \& Ibrahim, N. N. (2012). Indigenous Knowledge and Biodiversity Conservation in Sabah, Malaysia. International Journal of Social Science and Humanity, 2(2), 159-163.

Hillel, D. (Ed.). (2005). Encyclopedia of Soils in the Environment. Elsevier Ltd.

Hobson, G. (1992). Traditional Knowledge Is Science. ICSU.

Hosen, N., Nakamura, H., \& Hamzah, A. (2019). Traditional Ecological Knowledge and Climate Change Adaptation: The Sa'ban experience. Journal of ASIAN Behavioural Studies, $4(14)$.

Hosen, N., Nakamura, H., \& Hamzah, A. (2020). Adaptation to Climate Change : Does Traditional Ecological Knowledge Hold the Key ? Sustainability, $12,676$.

Houde, N. (2007). The six faces of traditional ecological knowledge: Challenges and opportunities for Canadian co-management arrangements. Ecology and Society, 12(2).

Ingty, T. (2017). High mountain communities and climate change: adaptation, traditional ecological knowledge, and institutions. Climatic Change, 145(1-2), 41-55

IPCC. (2014a). Climate Change 2014: Synthesis Report. WMO and UNEP.

IPCC. (2014b). Glossary. In Intergovernmental Panel on Climate Change.

Kettle, N. P., \& Dow, K. (2014). Cross-level differences and similarities in coastal climate change adaptation planning. Environmental Science and Policy, 44, 279-290.

Leonard, S., Parsons, M., Olawsky, K., \& Kofod, F. (2013). The role of culture and traditional knowledge in climate change adaptation: Insights from East Kimberley, Australia. Global Environmental Change, 23(3), 623-632.

Magni, G. (2016). Indigenous knowledge and implications for the sustainable development agenda (Global Education Monitoring Report).

Mazzocchi, F. (2006). Western science and traditional knowledge. EMBO Reports (European Molecular Biology Organization), 7(5), 463-466.

McGregor, D. (2004). Traditional ecological knowledge and sustainable development: towards co-existence. In M. Blaser, H. A. Feit, \& G. McRae (Eds.), In the Way of Development. Indigenous Peoples, Life Projects and Globalization (pp. 72-91). London, UK; New York, NY, USA: Zed Books.

McLean, K. G. (2012). Land Use, Climate Change Adaptation and Indigenous Peoples - Our World. United Nations University.

McMillen, H. L., Ticktin, T., Friedlander, A., Jupiter, S. D., Thaman, R., Campbell, J., Veitayaki, J., Giambelluca, T., Nihmei, S., Rupeni, E., Apis-Overhoff, L., Aalbersberg, W., \& Orcherton, D. F. (2014). Small islands, valuable insights: Systems of customary resource use and resilience to climate change in the Pacific. Ecology and Society, 19(4).

McMillen, H., Ticktin, T., \& Springer, H. K. (2017). The future is behind us: traditional ecological knowledge and resilience over time on Hawai'i Island. Regional Environmental Change, 17(2), 579-592.

Nakashima, D.J., Galloway McLean, K., Thulstrup, H.D., Ramos Castillo, A. and Rubis, J. T. (2012). Weathering Uncertainty: Traditional Knowledge for Climate Change Assessment and Adaptation (D. McDonald (Ed.)). UNESCO and UNU-TKI.

Nalau, J., Becken, S., Schliephack, J., Parsons, M., Brown, C., \& Mackey, B. (2018). The role of indigenous and traditional knowledge in ecosystem-based adaptation: A review of the literature and case studies from the Pacific Islands. Weather, Climate, and Society, 10(4), 851-865.

Nicholas-Figueroa, L. (2017). Traditional Ecological Knowledge of Stem Concepts in Informal and Place-based Western Educational Systems: Lessons from The North Slope, Alaska. University of Alaska Fairbanks.

Parrotta, J. A., \& Agnoletti, M. (2012). Traditional forest-related knowledge and climate change. In J. A. Parrotta \& R. L. Trosper (Eds.), Traditional forest-related knowledge: sustaining communities, ecosystems and biocultural diversity (pp. 491-534). Springer.

Pierotti, R., \& Wildcat, D. (2000). Traditional ecological knowledge: The third alternative (commentary). Ecological Applications, 10(5), $1333-1340$. 
Popp, J. N., Priadka, P., \& Kozmik, C. (2019). The rise of moose co-management and integration of Indigenous knowledge. Human Dimensions of Wildlife, 24(2), 159167

Prasad, N., Ranghieri, F., Shah, F., Trohanis, Z., Kessler, E., \& Sinha, R. (2009). Climate Resilient Cities: A Primer on Reducing Vulnerabilities to Disasters. The World Bank.

Prober, S. M., O'Connor, M. H., \& Walsh, F. J. (2011). Australian Aboriginal peoples' seasonal knowledge: A potential basis for shared understanding in environmental management. Ecology and Society, 16(2).

Raygorodetsky, G. (2011). Why Traditional Knowledge Holds the Key to Climate Change. UNU-TKI.

Salick, J., \& Byg, A. (2007). Indigenous peoples and climate change. In Tyndall Center for Climate Change Research, University of Oxford and Missouri Botanical Garden (Vol. 32, Issue 2).

Scaddan, C. (2008). Climate change and indigenous peoples. In United Nations Permanent Forum on Indigenous Issues. New York, NY, USA: United Nations

Scripps Institution of Oceanography. (2017). The Keeling Curve. Scripps Institution of Oceanography. https://scripps.ucsd.edu/programs/keelingcurve/

Swiderska, K., Reid, H., Song, Y., Li, J., Mutta, D., Ongugo, P., Pakia, M., Oros, R., \& Barriga, S. (2011). The Role of Traditional Knowledge and Crop Varieties in Adaptation to Climate Change and Food Security in SW China, Bolivian Andes and coastal Kenya. In UNU-IAS workshop on Indigenous Peoples, Marginalised Populations and Climate Change: Vulnerability, Adaptation and Traditional Knowledge.

Vinyeta, K., \& Lynn, K. (2013). Exploring the Role of Traditional Ecological Knowledge in Climate Change Initiatives. Portland, Oregon, USA: U.S Department of Agriculture, Forest Service, Pacific Northwest Research Station.

Walker, B. H., \& Salt, D. (2006). Resilience thinking: sustaining ecosystems and people in a changing world. Washington D.C, USA: Island Press.

Walker, B., Holling, C. S., Carpenter, S. R., \& Kinzig, A. (2004). Orientation and dynamics of a vesicle in tank-treading motion in shear flow. Ecology \& Society, 9(2).

Wildcat, D. R. (2014). Introduction: climate change and indigenous peoples of the USA. In J. K. Maldonado, B. Colombi, \& R. Pandya (Eds.), Climate Change and Indigenous Peoples in the United States: Impacts, Experiences and Actions (pp. 1-7). Switzerland: Springer International Publishing.

Ziegler, R. (2007). The Kula Ring of Bronislaw Malinowski: A simulation model of the co-evolution of an economic and ceremonial exchange system (Vol. 2007). 